\title{
Os usuários e a transição tecnológica no setor de saúde suplementar: estudo de caso de uma operadora de plano de saúde
}

\author{
Users and the technological transition in the supplemental health \\ sector: case study of a health insurance plan company
}

Consuelo Sampaio M eneses ${ }^{1}$

Luiz Carlos de Oliveira Cecilio ${ }^{1}$

RosemarieAndreazza ${ }^{1}$

ElianeCardoso de Araújo ${ }^{1}$

Aloísio Punhagui Cuginotti ${ }^{1}$

Ademar Arthur Chioro dos Reis ${ }^{2}$

${ }^{1}$ UniversidadeFederal de São Paulo (U nifesp). Rua Alfredo J osé Said 120, Jd. Botânico. 13106-284 Campinas SP.

clareia@superig.com.br ${ }^{2}$ Universidade

M etropolitana deSantos (Unimes).
Abstract This paper presents the results obtained from qualitative research conducted with a group of users involved in Case $M$ anagement, a program which was developed by a company of a medical group to provide healthcare for patients in situations of high vulnerability. The study sought to create a perspective in which the experience of the user, instead of representing merely additional or superimposed information upon thequality of services, is considered an inherent part of the arrangement under scrutiny, with theability to highlight its internal qualities and contradictions. The results show how patients attribute high value to the healthcare they receive, with special emphasis on the bond that is created with the health team in charge, even when contact is only by telephone. Simultaneously, they are able to perceive the double-sided aspect presented by the regulation/assistance model found in the technological arrangement at issue, notably in relation to the prominent role played by the economic bias towards cost reduction - which lies in the forefront of its operationalization - and the final impact it has upon the final quality of healthcare.

Key words Health policy, planning and manage ment, Supplemental healthcare services, Health management, $M$ anaged careprograms, Casemanagement, Organizational innovation
Resumo 0 artigo apresenta os resultados de investi gação realizada junto a usuários do case management, programa desenvolvido por uma empresa de medicina de grupo para o cuidado de pacientes vivendo situação de alta vulnerabilidade. Buscou-se construir uma perspectiva na qual a experiência do usuário, ao invés de representar apenasuma informação adicional ou superposta à qualidade dos serviços, é considerada parte indissociável do arranjo estudado, com potência para iluminar qualidades e contradições internas. Os resultados mostram como os pacientes dão alto valor aos cuidados recebidos, com especial ênfase no vínculo criado com a equipe responsável, mesmo que apenas por via tel efônica. Ao mesmo tempo, conseguem perceber a dupla face regulação/ modelo assi stencial presente no arranjo tecnológico estudado, sobretudo o quanto o forte viés econômico de redução decusto que presidesua operacionalização impacta na qualidade final do cuidado. Palavras-chaves Políticas, Planejamento e administração em saúde, Saúde suplementar, Gestão em saúde, Programas de atenção gerenciada, Case management, Inovação organizacional 
Introdução

Estudos vêm apontando como o discurso da Atenção Gerenciada (AG) ou M anaged Caretem inspirado a prática de novas formas de gestão do cuidado na saúde, com destaque para o descentramento dos processos decisórios da clínica para a esfera gerencial ${ }^{1,2}$. I sto se dá mediante tecnologias de gestão organizacional que buscam impactar a hegemonia e a autonomia da prática médica e dos seus padrões de incorporação tecnológica a partir de processos produtivos que prescindam de intervenções custosas, o que está se difundindo paulatinamente entre as operadoras do mercado de Saúde Suplementar brasileiro, por meio de dispositivos de microrregulação do mercado e de novos arranjos assistenciais ${ }^{3-6}$.

Baseadas nessas novas concepções de gestão do cuidado em saúde voltadas para a otimização da relação entre custo e qualidade, algumas empresas vêm introduzindo novas modalidades de assistência ao beneficiário que se assemelham a ensaios experimentais do que tem sido denominado de Transição Tecnológica (TT).

Compreende-se TT como um processo de inovação etransformação tecnológica que busca implementar um reordenamento na lógica dos processos assistenciais, modificando a composição das modalidades tecnológicas neles presentes. I sso corresponde ao aperfeiçoamento de técnicas que resultem na redução eno controle dos processos centrados no trabalho médico e seus corolários (alta utilização dos serviços e incorporação de tecnologias sob a forma de equipamentos) $)^{4,6-10}$; e, simultaneamente, a valorização detecnologias imateriais (relacionais ou "leves"), que se traduzem em práticas cuidadoras em tese centradas no usuário e suas necessidades.

As duas vertentes englobam, além de mecanismos de regulação do acesso, estratégias de desospitalização, gerenciamento de riscos, práticas de promoção e prevenção à saúde, uso de equipes multiprofissionais, e apontam, em seu conjunto, para a construção de um novo paradigma tecnológico nesse mercado.

Para isto, as empresas contam com um robusto aparato de mecanismos de regulação sobre prestadoreseusuários, dos quais o direcionamento declientela para prestadores preferenciais, prerrogativa da $A G^{11}$, é considerado o mais importante, impondo-se como verdadeira diretriz re gulatória, estruturante da funcionalidade operatória, econômica e assistencial do mercado. Assim, o direcionamento não apenas articula e ordena outros dispositivos microrregulatórios bem conhecidos (autorizações prévias, coparticipação dos usuários, adoção de "pacotes" no relacionamento com prestadores hospitalares, adoção de protocolos de cuidado, ferramentas de mensuração da performance médica etc) como constitui o arcabouço para a configuração das modelagens assistenciais onde se inscrevem práticas, em princípio, mais cuidadoras. A racionalidade econômica que orienta tal mecanismo em suas diversas formas torna-o vital para os processos de acumulação de capital no mercado de saúde e abre interrogações sobre o impacto que podem ter sobre a qualidade do cuidado produzido8.

A existência de uma legislação que coíbe restrições de acesso, além da inconveniência de um confronto direto com o consumidor que precisa ser disputado e conquistado no mercado de saúde, tornam menos visíveis as formas de regulação do acesso que incidem diretamente sobre os usuários. Para isto, são utilizados mecanismos de regulação "camuflados" (como credenciamento de redes de provedores, precificação de produtos onde se embutem fatores de proteção contra riscos futuros etc) articulados a práticas de prevenção e promoção à saúde, reunidas sob a insígnia da M edicina Preventiva $3,8,12$.

Este estudo tem como foco a perspectiva dos usuários no contexto anteriormente descrito, procurando estabelecer uma distinção com os de satisfação de usuários. Estes ganharam destaque a partir da década de 1970, quando a satisfação dos usuários do setor da saúde tornou-se tanto uma meta a ser alcançada pelos administradores como o foco de estudos acadêmicos voltados para a avaliação de serviços, embora tenha sido apontada por alguns autores a ausência de um referencial teórico-metodológico mais elaborado no sentido de fornecer um modelo conceitual consistente para a complexidade própria ao campo da saúde ${ }^{13,14}$.

N os modelosteóricos sobre avaliação existentes, o conceito de satisfação tem sido pouco teorizado, admitindo uma polissemia que esvazia sua dimensão analítica, podendo ser aplicado indistintamente a diversos aspectos dos serviços, inclusiveos não diretamenteligados à produção do cuidado. Tais estudos restringem-se a uma abordagem de variáveis necessárias à obtenção da satisfação do usuário eda sua fidelidade como consumidor, sem desenvolver uma compreensão mais profunda e analítica sobre a experiência real da interação entre o usuário e os serviços de saúd $\mathrm{e}^{13}$.

Esta investigação buscou construir uma perspectiva em que a experiência do usuário é considerada parte indissociável do projeto tecnoassis- 
tencial estudado, com potência para enriquecer a dimensão analítica do próprio processo de avaliação. Tal opção metodológica implicou em um esforço de ir além da avaliação linear e funcionalista, feita de forma isolada ou simultânea, de estrutura, processo e resultados, tal como tem sido pensado a partir dos estudos de Donabedian ${ }^{15,16}$.

Tendo como referencial teórico a dinâmica micropolítica dos processos de trabalho no contexto da reestruturação produtiva da Saúde Suplementar, o presente estudo tomou como problema central compreender a perspectiva do usuário em relação às estratégias de microrregulação vigentes no mercado e sua articulação com a transição tecnológica atual mente em curso. Teve como objetivo principal uma melhor compreensão de como o usuário percebe a influência dos mecanismos microrregulatórios sobre o cuidado que recebe e como el e sente e vivencia a experiência do cuidado nesses moldes.

\section{Metodologia}

Trata-se de um estudo qualitativo, tipo estudo de caso ${ }^{17}$ realizado em uma M edicina de Grupo de abrangência nacional. A pesquisa de campo foi realizada no município de São Paulo, com financiamento do Consel ho Nacional de Pesquisa (CN Pq).

Foram estudadas duas modalidades de cuidado apontadas pela equipe dirigente da empresa como representativas dos novos arranjos tecnológicos em curso: o casemanagement, destinado a pacientes de al to custo de planos de saúde específicos, ea "M edicina Preventiva", destinados aos casos crônicos, para todos os tipos de plano. Este artigo trata apenas dos achados referentes ao case management.

Para a análise dos dados, foram consideradas três "lugares" de observação do objeto: o lugar da formulação da política, ocupado pela alta direção da empresa; o lugar da implementação, ocupado pela equi pe que faz a gerência direta do case management; o lugar da utilização da estratégia, ocupado pelos usuários e o foco de atenção do estudo. As informações obtidas a partir de entrevistas semiestruturadas com esses diferentes atores, juntamente com análise documental, compuseram o material empírico analisado no presente artigo.

A pesquisa foi aprovada pelo Comitêde Ética da Universidade Federal de São Paulo. As entrevistas, realizadas entre junho a agosto de 2008, foram gravadas, precedidas da assinatura do termo de consentimento livre e esclarecido. Para o tratamento dos dados, foi utilizada a técnica de análise temática ou categorial como formulada por Bardin ${ }^{18}$, e que se baseia em operações de desmembramento do texto em unidades buscando descobrir os diferentes núcleos desentido que constituem a comunicação.

\section{O "case management" \\ e os usuários entrevistados}

O case management é um programa de gerenciamento telefônico de casos complexos, por meio do qual a operadora facilita o acesso do paciente ao recurso que apresenta melhor custobenefício dentro da rede de serviços. D esospitalização precoce, utilização preferencial deredeprópria ou credenciada de menor custo, utilização da rede referenciada e o seguimento domiciliar por equipe multidisciplinar compõem o arranjo tecnológico, com o objetivo declarado pela diretoria de redução de custos casada com um meIhor atendimento ao usuário.

O programa está diretamente ligado ao núcleo de "Gestão de Custos e Sinistros" da empresa, e contempla pacientes portadores de patologias de maior gravidade, "casos complexos" ou "custos inevitáveis", que representam al to custo para a operadora. A essência não declarada do programa é direcionar os beneficiários dos planos "top" e "intermediários", utilizadores da rede credenciada, para a rede própria da operadora ou para prestadores de menor custo.

0 número de casos ativos no programa era de 250 (duzentos e cinquenta), em abril de 2008, em um universo de aproximadamente 1,3 miIhão de beneficiários.

0 case management é uma tecnologia de gestão cujos elementos mais evidentes são a construção de vínculo eresponsabilização de uma equipe ("núcleo de atendimento") composta por 8 enfermeiras e um médico que realiza o seguimento de um grupo selecionado de pacientes, visando a gestão mais articulada e contínua no tempo dos cuidados necessários, sempre monitorados à distância, via contatos telefônicos regulares.

A equipe do "núcleo de atendimento" realiza o gerenciamento visando facilitar o acesso a medicamentos e outras tecnologias mais caras, bem como a liberação de autorizações prévias para exames e internações, sempre incentivando o direcionamento para hospitais de menor custo, ou para aqueles escolhidos pelos usuários, conforme o seu quadro clínico e/ou sua disposição para fazer valer sua escolha. Atua sempre no sentido de estabel ecer vínculo com o paci entee sua famí- 
lia econquistar sua confiança, garantir a fidelização e a adesão ao tratamento, o acompanhamento da equipe e o melhor encaminhamento para o caso, otimizando os recursos existentes.

A entrevista com a equipe do casemanagement possibilitou descrever tal arranjo echegar aos usuários, todos indicados pela equipe da operadora. Evidenciou-se, ao longo do processo de campo, que 0 aceite dos doentes, ou dos seus cuidadores, de fazerem seus depoimentos de vida poderia ser interpretado como indicação do vínculo (e relação de confiança) deles com a equipe do "case". $\mathrm{Não}$ obstante o reconhecimento de que esta forma de seleção dos usuários poderia exercer alguma influência sobreos resultados, foi possível perceber que as manifestações favoráveis e desfavoráveis em relação ao programa apresentaram-se de forma bastante regular em todos os casos estudados, a despeito de experiências de doença tão diferentes, já que todas representavam situações deextrema vulnerabilidadee dependência de cuidados de saúde. 0 pesquisador, por telefone, entrava em contato com o usuário, ou seu familiar e, após concordância, agendava a entrevista, realizada na casa do usuário sempre que possível. Foram indicados oito usuários, sendo que dois não concordaram em realizar a entrevista.

No Quadro 1, apresenta-se o perfil dosusuáriosentrevistados. M etodologicamenteoselementos de diferenciação e, também, o conjunto de semelhanças dos casos analisados permitiram a construção progressiva da amostra. Ou seja, foi possível a partir dos usuários estudados descobrir o que pode existir de geral em cada caso particular ${ }^{19}$. Eles apresentavam perfis clínicos que re queriam ações de alta complexidade e alto custo com itinerários diversos, tendo em comum a vivência de situações degrande perda de autonomia e acentuada dependência de cuidados complexos e contínuos no tempo.

Desse modo, ainda que o número de participantes não permita estabelecer generalizações amplas para todo o mercado, as características peculiares do grupo selecionado abrangeram um espectro de situações que possibilitaram não ape nas atender os objetivos da pesquisa como captar diversas dimensões do cuidado produzido.

Dadas as limitações das suas condições de saúde, os depoimentos foram obtidos, em sua maioria, dos cuidadores. Percebeu-sequeelestêm um senso critico apurado e exercem um papel protagonista nos processos microrregulatórios, especialmenteno quese refere ao acesso e consumo de uma complexa rede de serviços necessários ao cuidado.
Resultados

0 cuidado recebido

assume al to valor de uso

Os usuários do case management constituem uma população que recebe um tratamento diferenciado, seja pela gravidade dos casos, seja por representarem uma clientela de planos mais caros e, portanto, mais exigente de respostas efetivas aos seus problemas de saúde quando comparada à dos planos básicos. Em função disso, têm a prerrogativa da livre escolha do hospital para tratamento das suas patologias, com maior ou menor flexibilidade, a depender da modalidade do plano. De um modo geral, optam pela realização do tratamento em hospitais da rede credenciada a partir de critérios pessoais de preferência, quequase nunca coincidem com os critérios de base econômica utilizados pela operadora. Daí a necessidade de estratégias de direcionamento por parte desta última.

A escuta de usuários vivendo problemas de saúde mui to graves e bastante diferentes entresi, caracterizando situações-limite de vida, permitiu captar diversas dimensões do atendimento re cebido, em especial a percepção do quanto se sentem efetivamente cuidados e o reconhecimento da construção de vínculos efetivos entre eles e a equipe. Tal fato parece reforçar o pressuposto teórico adotado no estudo de que a transição tecnológica em curso apóia-se, entre outras coisas, na utilização crescente de tecnologias mais relacionais. Isto poderia resultar em um grau de reordenamento na utilização das tecnologias ditas "duras", particularmente o consumo de exames e procedimentos considerados desnecessários e onerosos pela operadora.

É possível identificar, nas manifestações dos entrevistados, o reconhecimento da produção de um "valor de uso" em relação a diferentes aspectos do cuidado recebido, conforme as ações implementadas venham ao encontro de suas necessidades, proporcionem algum grau de resolubilidade aos seus problemas ou tragam impacto na qualidade de suas vidas.

Em todos os depoimentos foi possível perceber o quanto a satisfação com as ações previstas nesta estratégia refere-se à produção de cuidado, traduzida pela percepção de sentir-se tratado de forma ao mesmo tempo humanizada e efetiva. Como afirma um usuário, É uma operadora que você é gente... a pessoa te trata como gente. (P2). Pacientes e familiares vivendo situações dramáticas de doença e perda de autonomia, com mu- 


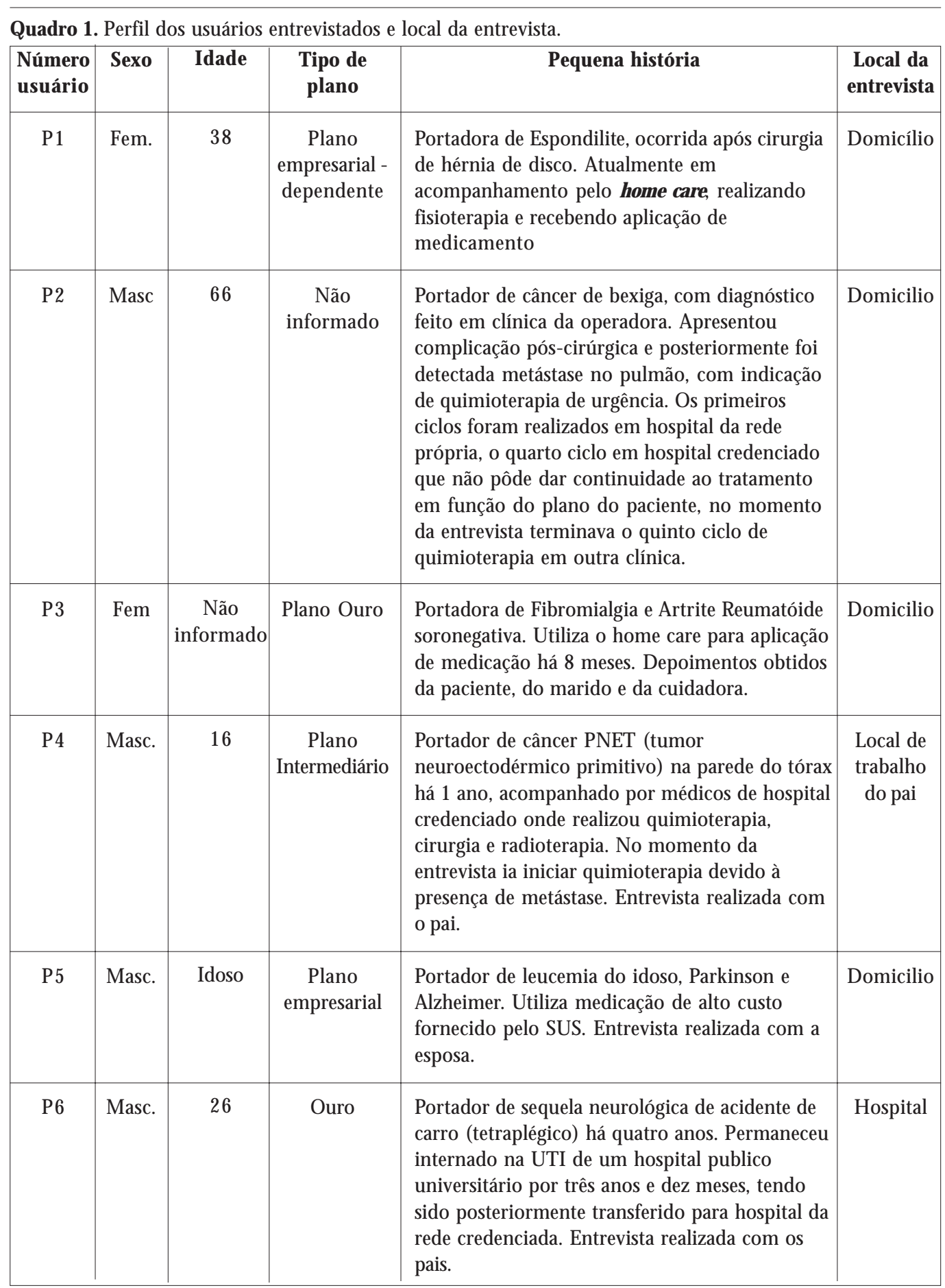

danças cotidianas drásticas, reconhecem isto de forma expressiva e consensual.

Chama a atenção, também, como os usuários, além de manifestarem satisfação pelo atendimento recebido, expressam um sentimento de reconhecimento e gratidão pelo que está sendo oferecido, inclusive quando não estão vincula- dos a planos considerados top, entendendo o cuidado recebido como uma generosidade da operadora Os depoimentos a seguir são exemplos destes sentimentos:

Estão nos atendendo maravilhosamente... A gente sente que el e está bem [o doente] enós também estamos. $\mathrm{N}$ ão tive nada até agora que dissesse 
quenão estou tendo cobertura. H oje, graçasa D eus, eu espero que não seja um sonho, que seja uma realidade [...] [e] até agora a gente está muito satisfeito (P6)

É sempre um conforto, porque ela tem uma grande dificuldade para se locomover... então pra ela é um conforto eles virem aqui trazer a medicação. Há uns 2 meses atrás ela não andava como anda agora. Então isso facilitou muito pra ela... (cuidadora P3)

Percebe-se que o valor de uso referido pelos usuários está especialmenteconcentrado em dois instrumentos utilizados pela operadora: (1) 0 chamado "núcleo de atendimento", equipe que operacionaliza especificamente 0 case management, e (2) o homecare, quenão é exclusivo desse arranjo assistencial, pois pode ser acionado a partir de outras demandas não geradas apenas pelo case.

As duas instâncias estão intimamente ligadas, a primeira acionando a segunda, sendo que para ambas converge a maior parte dos valores positivos atribuídos ao cuidado promovido neste arranjo tecnológico.

É notável que o relacionamento com o usuário baseia-se inteiramente no uso da voz (e suas diferentes modulações) dos membros da equipe, podendo haver rodízio do profissional que faz 0 atendimento para possibilitar melhor vínculo para cada caso. Isto significa que os usuários não conhecem pessoalmente os profissionais que compõem a equipe do case, o que confere uma relativa "impessoalidade" à relação estabelecida - o vínculo se constrói pela voz dos membros da equipe, um vínculo "sem face", não presencial, mas que aparentemente atende às necessidades de se sentir cuidado por parte dos pacientes.

Este vínculo não presencial não representa necessariamente uma queda de qualidade no serviço prestado, estabelecendo-se uma ligação pragmática e altamente resolutiva entre a equipe os pacientes. $\mathrm{H}$ ardt ${ }^{20}$ utiliza-se do conceito de trabalho afetivo para nomear os tipos de serviços que exigem a presença ou a proximidadefísica de outra pessoa - o que é essencial neleé a presença física, a criação e a manipulação de afetos. No entanto, o autor reconhece que "essa produção, troca e comunicação afetiva é geralmente associada ao contato humano, à presença efetiva de um outro, mas esse contato pode ser tanto real como virtual" (grifos nossos).

A criação do vínculo a partir do contato real ou virtual, é especialmente importante para essa categoria de usuários com perfil clínico de maior gravidade, dadas as queixas existentes em relação ao atendimento despersonalizado e massificado do call center. $O$ vínculo com a equipe cuidadora, mesmo quevirtual, éreconhecido como altamente positivo pelos usuários e écentral para a compreensão de sua satisfação e reconhecimento.

É tudo por tel efone. Eu nunca pensei em ir lá, porque não tem aonde ir, lá na central, eu vou falar com quem? Cada vez você fala com um atendenteeaí vocêcomeça a explicar, evocêfaz tudo de novo, e não dá certo de novo, evocêvai ligar efala com outro atendente. A cirurgia do... era muito séria. Eu estive a ponto de sair com uma metral hadora e chegar lá e metralhar todo mundo... porque quando se trata de um filho... Hoje quem tá me ajudando muito é o $\mathrm{N}$ úcleo de Atendimento que tem a enfermeira. Então, hoje, tudo o que eu preciso, eu primeiro converso com ela, entendeu? [...] Eu na verdade não quis nem entender. Como eles começaram a me ajudar... Na verdade, eu nem sei o queé estenúcleo, qual éa finalidadeeu não sei te responder. (P4)

Em alguns depoimentos, fica evidente que 0 paciente combina um "duplo vínculo", o (novo) vínculo com a equipe cuidadora eo (antigo) vínculo com médicos de sua confiança e escolha, pertencentes à rede credenciada, como écaracterístico dessa modalidade de plano que permite livre acesso. Os usuários buscam ativamente a construção de mais de um vínculo, compondo a "sua" rede de cuidado, em função de suas escoIhas e necessidades. Pode-se dizer que os usuários constroem uma rede de vínculo que Ihes possibilite mais segurança e variedades de opções em momentos diferentes da vida. Como se observa nesse depoimento:

Eu tenho 3 médicos, um neuro, um reumato e um neurocirurgião. (P3).

0 médico da [operadora] a gente não usa, [pois] ela já tem o médico dela... (cuidadora P3)

0 vínculo que se estabelece com a equipe do case management torna-se vital para a solução dos problemas que aparecem na trajetória de cada paciente, constituindo-se como o único vínculo possível com a estrutura organizacional da operadora. Há geralmente menção a um profissional que faz parte da equipe cuidadora e que é identificado como o responsável por "fazer as coisas acontecerem", sen do ele sua referência principal. Esse caráter não presencial do vínculo parece incomodar pouco o paciente ou seus familiares, desde que haja respostas efetivas às demandas apresentadas. Tais respostas, em geral avaliadas como positivas, são interpretadas como um vínculo real, como uma relação de amizade ou como uma concessão de atenção ou de favores 
da equipe. Um indicativo da força de tal vínculo é a satisfação, relatada por vários pacientes, de terem sua voz reconhecida do outro lado do telefone e serem chamados pelo nome ao ligarem para a equipe. Do mesmo modo, com o tempo passam a chamar pelo nome os profissionais da equipe. Pode-se dizer, portanto, que a base tecnológica desse arranjo é claramente do tipo relacional, produtora de cuidado e de vínculo, utilizando-se de tecnologias imateriais ou leves do cuidado em saúde, elemento importante do processo detransição tecnológica experimentado pela operadorå. Tal como nos revela este usuário:

Pra mim, funciona, porque nós fizemos amizade com a senhora... N em conheço, só por telefone. E tudo o que ela pode fazer, ela faz. (P3)

Como o tratamento eacompanhamento desses pacientes são realizados principalmente por médicos da rede credenciada, o contato assistencial com os serviços da operadora dá-se principal mentevia atendimento domiciliar (homecare) para evitar a internação ou reinternação em serviços não próprios. 0 reconhecimento da importância do home care como estratégia cuidadora de al to impacto foi unânime pelos entrevistados em função das suas dramáticas condições de vulnerabilidade e perda de autonomia. Tal depoimento expressa bem esta questão:

O serviço do home care é excelente... eu estou internado há 2 semanas, eu não aguento mais comida de hospital, não aguento ficar no hospital... eles vão até em casa! Tem coisa melhor do que ser tratado em casa? Ainda mais pobre, onde é que pobre tem enfermeiro em casa? N ão tem! (P4)

Acionado pela equipe do case, émuito valorizado por aqueles pacientes com pouca ou nenhuma condição de deslocamento para dar continuidade ao tratamento instituído ou nas situações que exigem cuidados multiprofissionais. A equipe do case também providencia o acesso a outros espaços de cuidados, a procedimentos de média e alta complexidade e parte dos insumos (bolsas, material para curativo e medicamentos em geral) que o paciente necessita.

A possibilidade de receber o tratamento em domicílio, via homecare, éconsiderado "um luxo" por alguns dos entrevistados, parte deles vivendo situações-limite defragilidadee de dependência de cuidados de saúde. Por tudo isto é possível afirmar que a estratégia u sada apresenta al to valor de uso para os seus beneficiários.
A apreensão da dupla face

regulação-qualificação do cuidado:

vivenciando o sentido

e as contradições da proposta

Apesar de prevalecer uma avaliação positiva do cuidado recebido, a escuta dos usuários propiciou a caracterização de algumas limitações de acesso a serviços e a tecnologias, alguns minimizados, mas não inteiramente solucionados, pelo núcleo de atendimento do case. Ou seja, apesar de muitos depoimentos val orizarem os ben efícios advindos do case, é possível identificar críticas quanto ao atendimento, tanto no relato dos pacientes, como no dos cuidadores. Tais manifestações, feitas de forma bastante enfática, principalmente pelos segundos, eram muitas vezes permeadas de grandesofrimento eindignação, efrequentemente destoaram do tom elogioso que vinha sendo mantido até determinado ponto das entrevistas.

Entre alguns dos problemas apontados, citam-se a dificuldade de cobertura pelos planos de alguns materiais, medicações e exames; a demora nas autorizações para procedimentos e internações com o consequente impedimento da instituição de tratamentos prescritos ou a descontinuidade de alguns já iniciados, bem como as insuficiências na atuação do home care. Como se percebe neste depoimento:

Eu já tive vários problemas (...). Ele tem que tomar um remédio, lá no hospital [ele] estava tomando ... [ eleestava] internado. Ele[foi] para casa e em casa o convênio não quis liberar este remédio pra ele. 0 hospital foi me cobrar dois comprimidos que ele tomou lá, no caso do hospital... R \$1300! (P4)

Tais dificuldades devem-se à presença de mecanismosmicrorregulatórios da utilização de serviços visando o controle dos custos, sobretudo hospitalar, tendo como denominador comum 0 direcionamento para prestadores preferenciais, consequente à racionalidade econômica que está na base do acúmulo de capital no setor.

A dificuldade para obtenção de autorizações prévias para procedimentos e internações, ligadas à tramitação burocrática que interferem na agilidade e no acesso aos serviços e procedimentos - um dispositivo regulatório bastante utilizado - é frequentemente citada. Pode ser considerada como o principal elemento de desgaste na relação usuário-operadora, assim como as demoras na liberação de autorização para exames ou as idas e voltas no processo de marcação de procedimentos. É assim que este paciente ex- 
pressa a compreensão destes mecanismos microrregulatórios:

Os convênios são todos iguais... é demorado, não libera... demora pra liberar... tem hora que penso que a intenção do convenio é fazer isso de propósito... [as burocracias] para desistir do convênio. (P4)

O direcionamento como núcleo da prática regulatória e assistencial

Os relatos deixam evidentea vinculação existente entre as autorizações prévias e o direcionamento para prestadores preferenciais como 0 cerne desse desenho organizacional, sobretudo ao considerarmos o perfil dessa clientela, quetem, ao menos formalmente, a prerrogativa da livre escolha dos seus prestadores. Na prática, e o estudo mostra bem isso, o beneficiário do plano precisa constantemente enfrentar as estratégias direcionadoras da operadora.

O direcionamento para prestadores de menor custo via autorização prévia é condicionado pela gradação de possibilidade de livre-escolha dos prestadores pelos usuários, que varia conforme o tipo de plano. A indução regulatória para o uso da rede própria ou de prestadores da rede credenciada menos onerosos é sempre experimentada, porém parece diminuir conforme se dá o deslocamento dos planos intermediários para os planos top. A equipe do case sempre se envolve em algum trabalho de convencimento sobre o uso da rede de prestadores, a partir de uma perspectiva econômica mais favorável à operadora.

Pode-se observar que a aplicação desses mecanismos microrregulatórios nos casos estudados interfere, de modo bem reconhecido pelos usuários, na viabilização de ligações vitais para a produção do cuidado e, portanto, na integralidade e na qualidade da assistência prestada. Tal afirmação pode ser exemplificada com o caso do paciente (P2) que estava tendo sessões de quimioterapia em serviços diferentes, com equipes diferentes, de acordo com os interesses da operadora, sem levar em consideração a importância da criação devínculo paciente/equipe. H ouveainda relatos de demora para envio à instituição de terapêuticas urgentes em situações de risco de vida e a interrupção de tratamentos já iniciados, resultando em complicações clínicas diversas em vista de tais práticas organizacionais. Eis alguns exemplos:
Começou a querer negar mais coisas. Primeiro a internação. Falavam que não tinha vaga, que tinha uma outra classe de hospital que poderia aceitar ela sem ser o que o plano dela cobre. Queriam um tempo, tanto é que ela saiu daqui com o médico falando que ‘não vai ficar mais que 5 dias internada'. E no fim foram 28 dias. 0 convênio enrolando para começar a cirurgia (já internada). No fim, acabou pegando pneumonia no hospital, ela adquiriu outros problemas lá, ela tinha uma pequena escara no cóccix e essa escara abriu. Tudo isso esperando ser liberada essa cirurgia que nunca liberavam. Deu trabalho. (cuidadora P3)

Ele ia ser internado [para quimioterapia] e falaram que não tinha condições de internar, porque o convênio estava 'desconveniando' o hospital. Eles queriam transferir para o hospital próprio. N ossa, eu fiquei quasemaluco lá. Eu falei um monte de palavrão, porquenão teve jeito, dava vontade de dar soco na parede, dava vontade de dar soco naquele pessoal. Ele tá fazendo tratamento aqui desdesetembro e vocêsvão transferir o meu filho??!!! Os médicos que estão cuidando do meu filho estão aqui!!! Vocês estão me falando que o convênio tá descredenciando o hospital hoje? E vocês estão me avisando hoje, domingo? E amanhã, feriado?! Com ordem dequem??!! (P4)

Outras observações são atinentes à qualidade dos serviços prestados na assistência domiciliar pelo home care, cujas ações são realizadas por empresas terceirizadas. Foram citados problemas relativos à precipitação de al tas hospitalares e atraso de medicação pelo home care, com necessidade de reinternação (P1); demora para início do primeiro atendimento pelo home care; ênfase no não comparecimento da equipe aos retornos agendados ou mesmo não comparecimento ao primeiro atendimento domiciliar ( $\mathrm{P} 2 \mathrm{e}$ P3); imperícia da equipe na realização de procedimentos como venóclise, etc (P4). Tais proble mas podem ser basicamente atribuídos ao fato de não existir uma coordenação da ação pela operadora, sendo possível observar como a tercei rização, estratégia racionalizadora da operadora, pode impactar negativamente na qualidade do atendimento. Ou seja, a gestão inadequada do home care compromete o funcionamento desse arranjo, entre outras coisas, devido à não observância ou à falta de clareza de critérios para a desospitalização, à precarização do vínculo e à qualidade do cuidado prestado, aqui se incluindo a descontinuidade do atendimento e a precária qualificação técnica da equipe. 
A percepção dos pacientes sobre as razões do atual formato do modelo de atenção

As entrevistas trouxeram importantes elementos que confirmam que o usuário interroga, vêecompreen dea relação existente entre o desenho assistencial e a microrregulação. É possível perceber como os usuários, mesmo os mais gratos e satisfeitos, identificam claramente o case management como uma estratégia de redução de custos, tendo o direcionamento como o centro da ação regulatória.

Eu achei que era economia, porque ele ficou internado 10 dias no... [credenciado], deve ter custado muito caro pro convênio. E se eles mandarem a ambulância, eles não vão levar no hospital que eu quero, só no... [ próprio]. (cuidadora P5)

O conjunto de dispositivos microrregulatórios utilizados nesta operadora relaciona-se ao que a sua al ta direção denomina tight control, no sentido de buscar o controle total sobre todas as etapas do processo de produção do cuidado. I sso significa, na prática, manter o controle do itinerário do paciente em limites bastante estreitos, traduzindo a ideia de direcionamento como um elemento central do processo microrregulatório da operadora. 0 tight control tende a capturar todas as possibilidades ao seu al cance: a autonomia do médico, da equipe, do usuário, enfim, tudo o que se possa caracterizar como "trabalho vivo", configurando uma lógica de controle de custos e de desperdício comprometida com os objetivos comerciais da empresa.

Como estratégia de "inteligência” organizacional vital para a operadora, essa lógica mostra-se agudamente presente no arranjo assistencial estudado, visando garantir a previsibilidade dos custos mediante ações que têm como pano de fundo o direcionamento. Entre essas ações, podem ser citadas a desospitalização precoce, a utilização da rede própria ou credenciada de menor custo, a regulação da utilização da redereferenciada e o encaminhamento para a equipe multidisciplinar domiciliar. A justificativa para a sua utilização é "embalar o clienteem um modelo seguro", ainda que isto não seja oferecido a todos, somente "a quem precisa", segundo os dirigentes.

A seu modo, os usuários parecem captar, com clareza, a ligação entre o modelo assistencial, reconhecido como produtor de valor de uso, e o processo de microrregulação, de base econômica e racionalizadora, e as tensões que se estabelecem entre eles. Por isso, elogios e manifestações de gratidão em relação ao cuidado prestado por esta operadora não obscurecem a percepção que eles têm a respeito da dupla face regulação/qualificação do cuidado.

\section{Consideraçõesfinais}

O estudo permitiu explorar a molecularidade do case management, que pode ser considerado um dos elementos de um processo mais amplo de TT experimentado pela operadora estudada. Tais ensaios de TT têm si do observados de forma disseminada na saúde suplementar como forma de fazer frente aos custos crescentes com assistência e debuscar estabilidade em um segmento econômico cada vez mais competitivo ecrescentemente regulamentado pela Agência N acional de Saúde Suplementar (ANS).

O que se observou no estudo foi uma efetiva produção de valor de uso para os usuários a partir de tecnologias cuidadoras e produtoras de vínculo, mesmo que virtual, ainda que a operacionalização do arranjo seja bastante modulada pelas estratégias racional izadoras, sobretudo o direcionamento ea terceirização de serviços. Tais estraté gias de caráter eficientista comandadas pela lógica econômica das operadoras parecem influenciar negativamente a qualidade do cuidado final e a percepção dos usuários sobre tais processos. Nesse contexto, o aprimoramento da gestão do homecare, uma das tecnologias que dão amparo ao programa, embora não seja exclusivo deste, poderia contribuir mais positivamente para esta percepção e para o próprio cuidado, ainda que não neutralizeos efeitos do direcionamento, essencial para a gestão da utilização da rede credenciada.

Há, assim, um sentimento de ambiguidade em relação ao cuidado recebido. Ao mesmo tempo em que os pacientes apontam problemas e manifestam críticas, sentem-se agradecidos pelo que consideram benefícios. Talvez o aparente paradoxo esteja relacionado à condição de sofrimento e fragilidade emocional que grande parte desses pacientes e cuidadores vivenciam, sobretudo os que não dispõem de um plano top e se sentem favorecidos por ações de custo elevado a que só teriam acesso, segundo acreditam, mediante pagamento direto.

Ao lado das manifestações de reconhecimento e gratidão, fica, porém, latente a contradição entre a percepção do cuidado recebido como um direito, quelhes daria a segurança da continuidade, ou como fruto da benevolência da operadora, que poderia ser retirado a qualquer momento.

A escuta dos usuários mostrou que, embora o casemanagement produza inquestionável valor 
de uso, os problemas apontados são relacionados justamente às consequências da sua ação regulatória. E, nesse sentido, os achados da pesquisa mostram o quanto o direcionamento, diretriz organizacional imprescindível para a rentabilidade do setor, causa sempre apreensão e dúvidas nos usuários em relação aos seus direitos reais, por conta das quase sempre duras ne gociações/enfrentamentos que precisam travar com a operadora quando renovadas necessidades se apresentam.

\section{Referências}

1. Iriart CB. Atenção Gerenciada: Instituinte da Reforma Neoliberal [tese]. Campinas (SP): Universidade Estadual de Campinas; 1999.

2. Iriart $\mathrm{CB}, \mathrm{M}$ erhy EE, Waitzkin $\mathrm{H}$. Managed care in Latin America: the new common sense in health reform. Social Science \& M edicine 2001; 52(8):12431253.

3. Malta DC, Cecílio LCO, Jorge AO, Aciole GG, organizadores. Duas faces da mesma moeda: Microrre gulação e M odelos Assistenciais na Saúde Suplementar. Rio de Janeiro: AN S/M S; 2005 (Série A. Normas e M anuais Técnicos - Regulação e Saúde 4)

4. Kongstvedt PR. Physician behavior change in $\mathrm{Ma}$ naged $\mathrm{H}$ ealth $\mathrm{C}$ are. In: Kongstvedt PR, organizador. Essentials of managed health care. $4^{\text {th }}$ Edition. London (UK): Jones and Bartlett Publishers Internacional; 2003. p. 419-438.

5. Smith RI, Thornton D, Sollon T. Examining common assertion about managed care. In: Kongstvedt $P R$, organizador. Essentials of managed health care. $4^{\text {th }}$ Edition. London (UK): Jones and Bartlett Publishers Internacional; 2003. p. 71-82.

6. Waitzkin H, Fishman J. Inside of system: The patient-physician relashionship in the era of managed care. In: Wilkerson C, Devers K, Given R, organizadores. Competitive $\mathrm{M}$ anaged Care: The Emerging $\mathrm{H}$ ealth Care System. San Francisco: Jossey-Bass; 1997. p. 136-161.

7. Merhy EE. Saúde: a cartografia do trabalho vivo. São Paulo: Hucitec; 2002.

8. Meneses CS. M ercado de saúde no Brasil, qualificação assistencial e transição tecnológica: um desafio regulatório para o Estado [tese]. Campinas (SP): Universidade Estadual de Campinas; 2004.

9. Poullier JP. El afan por la eficiencia. Rev. Econ. Reformas Sanitarias Actuales 1990; 7(26):681-682.

10. Altman SH, Rodwin A. Halfway competitive markets and ineffective regulation: the american health care system. In: Greenberg W, editor. Competition in the health care sector: ten years later. Durham: Duke University Press; 1988. p. 101-117.

\section{Colaboradores}

CS M eneses participou da concepção e fundamentação teórica da pesquisa, da metodologia, da análise dos dados e da redação final; LCO Cecílio foi o coordenador da pesquisa e participou da concepção, da metodologia, da análise dos dados e da redação final; AAC Reis e AP Cuginotti participaram da metodologia eda análise dos dados; EC Araújo e R Andreazza participaram da metodologia, da análise dos achados $e$ da redação.
11. Ugá MS, Santos AM P, Pinto MTF, Porto SM . A regulação da atenção à saúde nos EUA. In: Brasil. Ministério da Saúde (MS). Agência Nacional de Saúde Suplementar (ANS). Regulação \& Saúde: estrutura, evolução e perspectivas da assistência médica suple mentar. Rio de Janeiro: ANS; 2002. p. 237-254.

12. Bahia AL. O mercado de planos e seguros de saúde no Brasil: tendências pós-regulamentação. In: $\mathrm{Ne}$ gri B, Giovanni G, organizadores. Brasil: radiografia da saúde. Campinas: Universidade Estadual de Campinas, Instituto de Economia; 2001. p. 325-361.

13. Esperidião MA, Trad LAB. Avaliação de Satisfação de U suários: considerações teórico-conceituais. Cad Saude Publica 2006; 22(6):1267-1276.

14. Denis JL, Champagne F. Análise da Implantação. In: Hartz ZM A, organizadora. Avaliação em Saúde: Dos Modelos Conceituais à Prática na Análise da Implantação de Programas. Rio de Janeiro: Fiocruz; 2000. p. 49-88. (1’a reimpressão revista).

15. Donabedian A. The Definition of Quality and Approaches to its Assessment. Ann Harbor (Michigan): Health Administration Press; 1980.

16. Donabedian A. The Seven Pillars of Quality. Arch Pathol Lab M ed 1990; 114(11):1115-1118.

17. Yin RK. Estudo de Caso: planejamento e métodos Trad. de Grassi D. 3a Edição. Porto Alegre: Bookman; 2005.

18. Bardin L. Análise de conteúdo. Lisboa: Edições 70; 2002.

19. Bertaux D. Narrativas de vida: a pesquisa e seus métodos. Natal, São Paulo: EDUFN, Paulus; 2010.

20. Hardt M. O trabalho afetivo. Cadernos de Subjetividade PUC-SP 1993; 1(1):143-157.

Artigo apresentado em 13/06/2011

Aprovado em 13/09/2011

Versão final apresentada em 19/09/2011 